\title{
Combined EBSD+EDS for Phase Differentiation in Zr/Steel Reaction Layers
}

\author{
Chad M. Parish, Kurt A. Terrani, Dongwon Shin, and Bruce A. Pint \\ Oak Ridge National Laboratory, Oak Ridge, TN, 37831, USA
}

Zirconium-based cladding materials such as Zircaloy, are standard in light-water reactors due to zirconium's combination of favorable neutronic and corrosion properties. However, in an accident condition resulting in temperatures above $\sim 1200^{\circ} \mathrm{C}$, the reaction of zirconium with $\mathrm{H}_{2} \mathrm{O}$ (steam) can proceed in a self-catalytic fashion at a very high rate, [1] converting the zirconium metal to zirconium oxide and evolving hydrogen gas, that can result in an explosion. In this work, a simple experiment was performed to test the ability of oxidation resistant stainless steel to avert such a reaction by preventing contact between zirconium and steam. Zirconium powder was canned in 310 stainless steel, subjected to hot isostatic pressing to consolidate the powder, and then reacted at high temperature under steam.

Although the results indicated rapid reaction kinetics between $\mathrm{Zr}$ and steel that makes such cladding unfeasible, complex reaction layers that formed at the $\mathrm{Zr} /$ steel interface provided a difficult test of the ability of EBSD to perform phase differentiation. Calculated phase diagrams from computational thermodynamics indicated the formation of several different hexagonal and cubic phases along with lower-symmetry phases. Possible phases resulting from the $\mathrm{Zr} / 310$ stainless steel (310SS) reaction are FCC steel $(\gamma$-Fe, Fm-3m, space group \#225), BCC $\alpha$-Cr or $\beta$-Zr (Im-3m, \#229), Fe 2 Zr cubic laves (Fd$3 \mathrm{~m}$, \#227), hexagonal $\alpha-\mathrm{Zr}$ (P6/ $/ \mathrm{mmc}$, \#194), $\mathrm{Cr}_{2} \mathrm{Zr}$ hexagonal laves (P63/mmc, \#194), tetragonal $\mathrm{Zr}_{2} \mathrm{Fe}$ (I4/mcm, \#140), tetragonal $\sigma-\mathrm{CrFe}\left(\mathrm{P}_{2} / \mathrm{mnm}\right.$, \#136), and orthorhombic $\mathrm{Zr}_{3} \mathrm{Fe}$ (Cmcm, \#63). Although the low symmetry phases $\left(\mathrm{Zr}_{2} \mathrm{Fe}, \mathrm{Zr}_{3} \mathrm{Fe}, \sigma-\mathrm{CrFe}\right)$ are sufficiently distinct that their EBSD patterns cannot be confused for other phases, the FCC phases $\left(\gamma\right.$-Fe, laves $\left.\mathrm{Fe}_{2} \mathrm{Zr}\right)$ are essentially indistinguishable via EBSD, and the hexagonal phases $\left(\alpha-Z r\right.$, laves $\left.\mathrm{Cr}_{2} \mathrm{Zr}\right)$ are difficult to differentiate due to their identical space group, although the c/a ratios and allowed reflections are different, making only low-confidence indexing possible. A backscattered electron (BSE) cross-section image of the $\mathrm{Zr} / 310 \mathrm{SS}$ sample treated at $1200^{\circ} \mathrm{C}$ in steam for $18 \mathrm{hrs}$ is shown in Fig. 1, along with an image quality (IQ) map, simultaneously acquired X-ray maps, and representative EBSD point patterns labeled 1-6. The low-symmetry phases are labeled unambiguously, but FCC phases ( $\gamma$-Fe vs. $\mathrm{Fe}_{2} \mathrm{Zr}$ ) and hexagonal phases $\left(\alpha-\mathrm{Zr}\right.$ vs. $\mathrm{Cr}_{2} \mathrm{Zr}$ ) cannot be differentiated. By taking advantage of the EDS data, however, these similar phases can be distinguished by adding chemical information to the diffraction information. [2, 3] The presence of $\mathrm{Zr}$ can be used to differentiate $\gamma-\mathrm{Fe}$ vs. $\mathrm{Fe}_{2} \mathrm{Zr}$, and the presence of $\mathrm{Cr}$ is used to differentiate $\alpha-\mathrm{Zr}$ vs. $\mathrm{Cr}_{2} \mathrm{Zr}$, as shown in Fig. 2, which shows clear phase differentiation.

By combining EDS and EBSD information from the same scan area, these eight phases, including several phases indistinguishable via EBSD alone, are clearly mapped across the diffusion couple, illustrating the power of combined EDS+EBSD [4].

[1] M. Moalem and D.R. Olander, J. Nucl. Mater., V182 (1991) P.170.

[2] M.M. Nowell and S. I. Wright, J. Micros., V213(3) (2004), P.296.

[3] C. M. Parish et al., Micros. Microan., V17(Suppl 2) (2011), P. 410.

[4] Supported by ORNL's Shared Research Equipment (ShaRE) User Facility, which is sponsored by the Office of Basic Energy Sciences, US Department of Energy (DOE), the Advanced Fuels Campaign of the Fuel Cycle R\&D Program, Office of Nuclear Energy, U.S. DOE, and the ORNL LDRD program. 

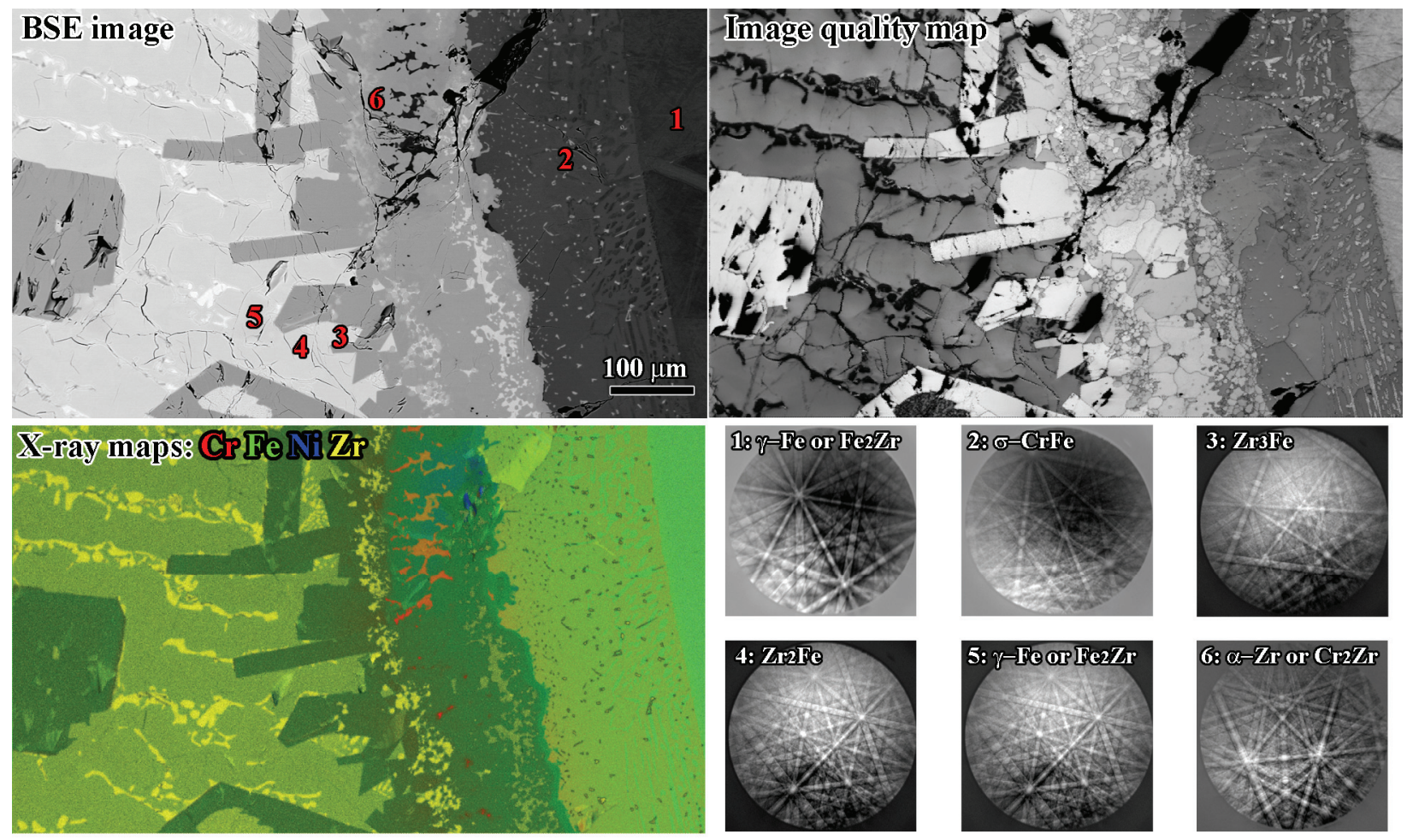

Figure 1. BSE image, image quality (IQ) map, X-ray maps, and point patterns.

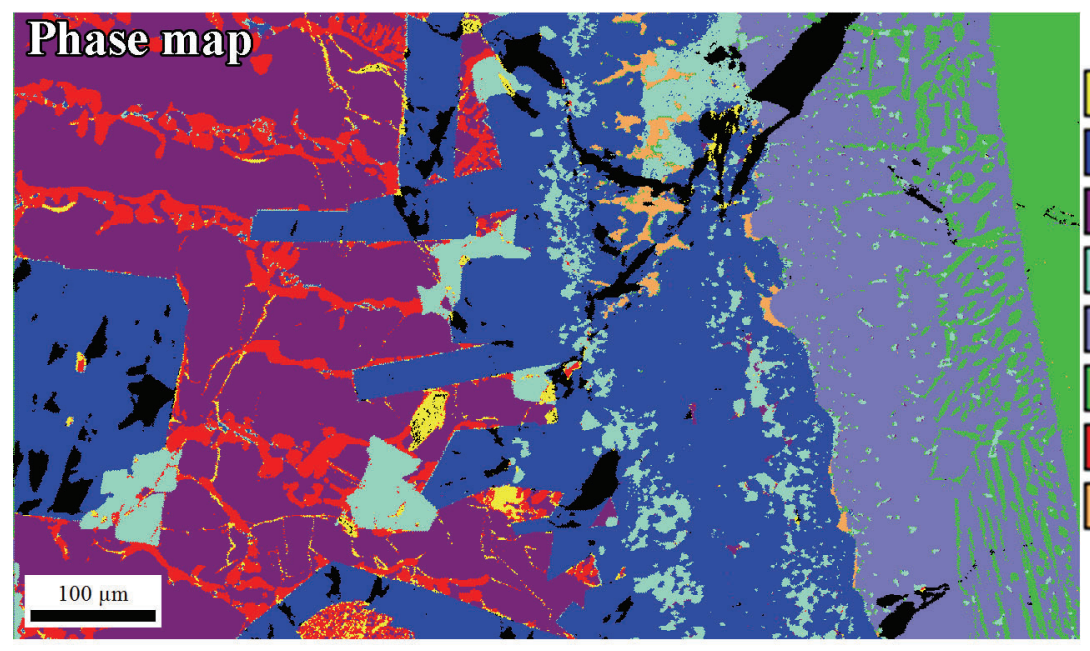

\begin{tabular}{|c|c|}
\hline ZrsFe & Figure 2: (top) \\
\hline Cr2Zr & Phase map and \\
\hline ZreFe & (bottom) image \\
\hline Fe2Zr & quality +inverse \\
\hline$\sigma-\operatorname{CrF}$ & $\begin{array}{l}\text { pole tigure (IPF) } \\
\text { maps. }\end{array}$ \\
\hline$\gamma$-Fe & \\
\hline$\alpha-\mathbf{Z r}$ & \\
\hline$\alpha-\mathbf{C r}$ & \\
\hline
\end{tabular}
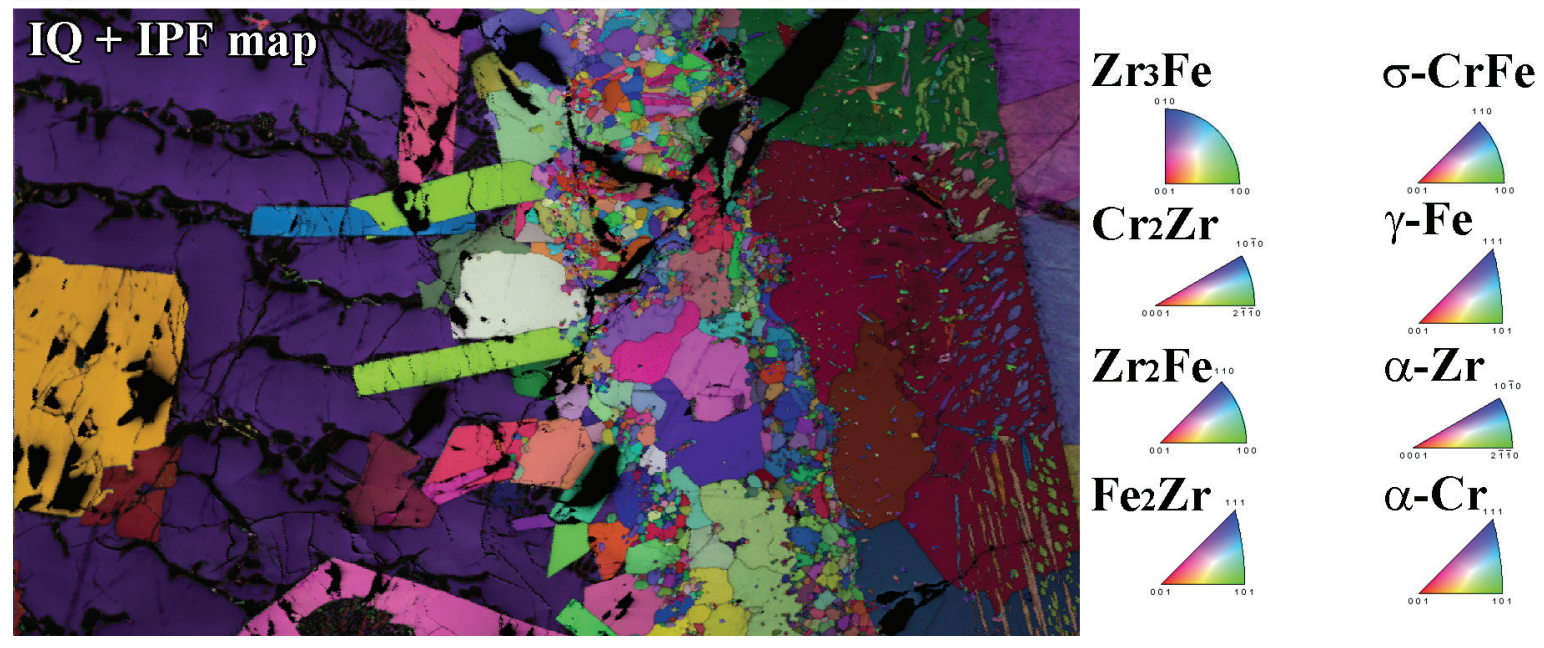